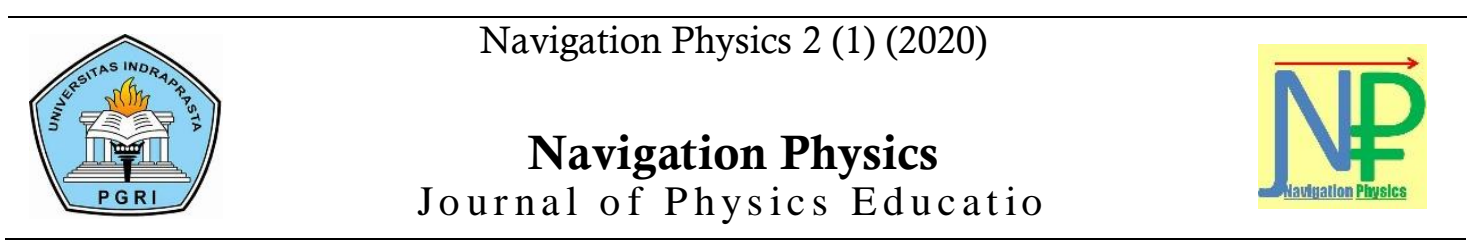

\title{
Perancangan Aplikasi Konversi Besaran Berbasis Matlab Untuk Mahasiswa Informatika
}

\author{
Alhidayuddiniyah, T.W ${ }^{1}$, Siwi Puji Astuti ${ }^{2}$ dan Santy Handayani ${ }^{3}$ \\ $1,2,3$ Universitas Indraprasta PGRI Jakarta \\ Email: alhida.dini@mail.com
}

\begin{tabular}{ll}
\hline Info Artikel & Abstract \\
\hline Sejarah Artikel: & Magnitude is a basic science of physics that is often found in everyday life. \\
Diterima April 2020 & Basically, the quantity is divided into two, namely the principal amount \\
Disetujui Mei 2020 & and the amount of the derivative. These quantities have their respective \\
Dipublikasikan Juni 2020 & sizes, where the size of a quantity can be converted. To help simplify the \\
& calculation and introduction of conversion systems, an application for the \\
Keywords: & conversion of principal and derivative quantities using Matlab is designed. \\
Physics, Matlab, Conversion & Besides being easy to use, this application can be an alternative learning \\
& medium in combining Physics with programming, as well as a GUI \\
designed to help conversion calculations.
\end{tabular}

How to Cite: Alhidayatuddiniyah., Astuti S.P., \& Handayani S. (2020). Perancangan aplikasi konversi besaran berbasis Matlab untuk mahasiswa informatika. Navigation Physics, 2 (1): 25-29.

\section{PENDAHULUAN}

Pada kegiatan belajar mengajar (KBM) diperlukan experimental learning. Namun, ada kalanya pada KBM dihadapkan pada materi yang tidak dapat dilakukan eksperimennya. (Alhidayatuddiniyah, dkk. 2018: ed3.1)

Ada banyak media yang dapat membantu dalam proses pembelajaran. Perangkat lunak untuk presentasi pun juga sudah familiar di masyarakat. Namun, perangkat lunak yang diperlukan untuk mendukung sarana belajar fisika dasar berbasis pemrograman, masih banyak belum diterapkan di Universitas. Sedangkan, sesuai dengan RPS yang ada, diharapkan mahasiswa Informatika yang mengikuti mata kuliah dasar Fisika Gerak mampu memahami materi perkuliahan dan mampu menerapkannya sesuai dengan jurusan yang ditempuh. Selain itu, dari hasil pengamatan, masih banyak mahasiswa yang tidak menyenangi mata kuliah fisika dikarenakan penyampaian materi saat awal pertemuan pertama kali kurang memotivasi semangat mahasiswa untuk mempelajari fisika.

Untuk menggambarkan suatu fenomena yang terjadi atau dialami suatu benda penggunaan media pembelajaran yang tepat sangat membantu dalam proses belajar mengajar. (Siwi P.A., dkk. 2019: 2)

Oleh sebab itu, berdasarkan permasalahan tersebut penelitian ini bertujuan untuk merancang bangun dan mendesain aplikasi konversi dengan menggunakan aplikasi Matlab, khususnya materi besaran pokok dan turunan.

\section{METODE PENELITIAN}

Metode penelitian yang digunakan dalam penelitian ini adalah studi literatur dan perancangan GUI menggunakan Matlab. Dasar-dasar teori yang mendukung digunakan sebagai konsep dasar pengukuran besaran dan satuan. Tampilan GUI disesuaikan dengan target dan capaian RPS Fisika Gerak dan dilengkapi dengan menu pilihan besaran pokok dan turunan, yang terdiri atas: panjang, massa, waktu, suhu, luas, dan volum.

Adapun alur kerja penelitian ini, yaitu: 


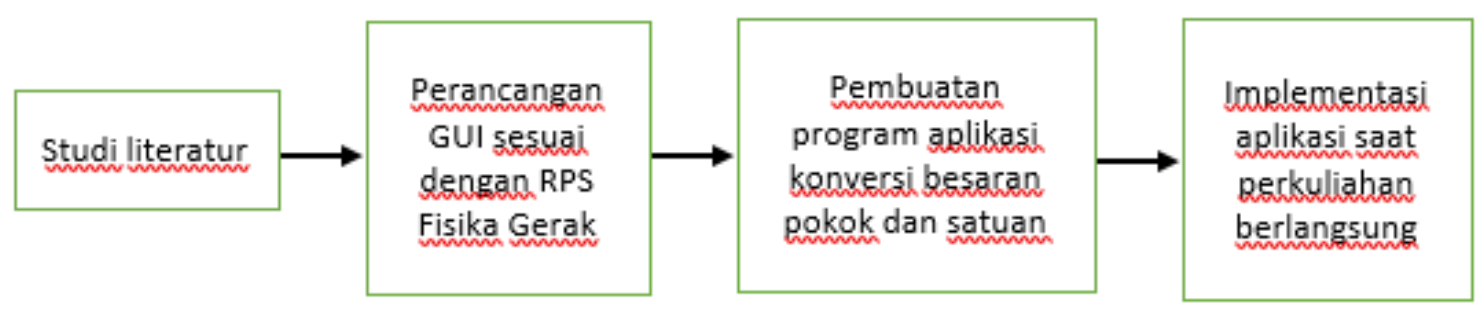

Gambar 1. Alur penelitian

Setelah produk aplikasi konversi besaran sudah selesai dibuat, penelitian ini diterapkan di Universitas Indraprasta saat sesi perkuliahan Fisika Gerak.

\section{HASIL DAN PEMBAHASAN}

Perancangan menu aplikasi dirancang sesuai dengan RPS mata kuliah Fisika Gerak untuk Jurusan Informatika, Universitas Indraprasta PGRI.

Tabel 1. RPS capaian materi pembelajaran besaran, satuan, dan pengukuran.

\begin{tabular}{|c|c|c|c|c|c|c|c|}
\hline $\begin{array}{l}\text { Minggu } \\
\text { ke }\end{array}$ & $\begin{array}{l}\text { Kemampuan yang } \\
\text { diharapkan } \\
\text { (Sub CP-MK) }\end{array}$ & $\begin{array}{c}\text { Bahan Kajian/ Materi } \\
\text { Pembelajaran }\end{array}$ & $\begin{array}{c}\text { Metode } \\
\text { Pembelajaran }\end{array}$ & Waktu & $\begin{array}{l}\text { Pengalaman Belajar } \\
\text { Mahasiswa }\end{array}$ & $\begin{array}{c}\text { Kriteria, Bentuk Penilaian } \\
\text { dan Indikator }\end{array}$ & $\begin{array}{c}\text { Bobot } \\
\text { Nilai }\end{array}$ \\
\hline (1) & $(2)$ & (3) & (4) & (5) & (6) & (7) & (8) \\
\hline 1 & $\begin{array}{l}\text { - Mahasiswa mampu } \\
\text { memahami dan } \\
\text { menjelaskan } \\
\text { besaran, satuan, } \\
\text { dan pengukuran. }\end{array}$ & $\begin{array}{l}\text { - Penjelasan SAP. } \\
\text { - Pembagian } \\
\text { kelompok tugas. } \\
\text { - Definisi besaran dan } \\
\text { satuan. } \\
\text { - Notasi ilmiah dan } \\
\text { konversi satuan. }\end{array}$ & $\begin{array}{l}\text { Discovery } \\
\text { Learning }\end{array}$ & $\begin{array}{l}\text { - } \mathrm{TM} ; 2 \times 50=100 \\
\text { menit } \\
\text { - } \\
\text { BT; } 2 \times 60=120 \\
\text { menit } \\
\text { - } \\
\text { BM; } 2 \times 50=100 \\
\text { menit }\end{array}$ & $\begin{array}{l}\text { Mempelajari } \\
\text { besaran pokok dan } \\
\text { turunan, satuan, dan } \\
\text { aturan pembulatan } \\
\text { dan angka penting, } \\
\text { serta metode } \\
\text { pengukuran. }\end{array}$ & $\begin{array}{l}\text { Indikator: } \\
\text { - Kelengkapan dan } \\
\text { kejelasan dalam } \\
\text { memahami dan } \\
\text { menjelaskan definisi } \\
\text { besaran dan } \\
\text { kelompoknya, satuan, } \\
\text { dan pengukuran. } \\
\text { Kriteria: } \\
\text { - Ketepatan dan } \\
\text { penguasaan masalah } \\
\text { Bentuk Penilaian: } \\
\text { - Tugas provek } \\
\end{array}$ & $6 \%$ \\
\hline
\end{tabular}

Materi penelitian ini meliputi konversi besaran pokok dan turunan. Konversi besaran pokok berisi konversi panjang, massa, waktu, dan suhu. Konversi besaran turunan berisi konversi luas dan volum.

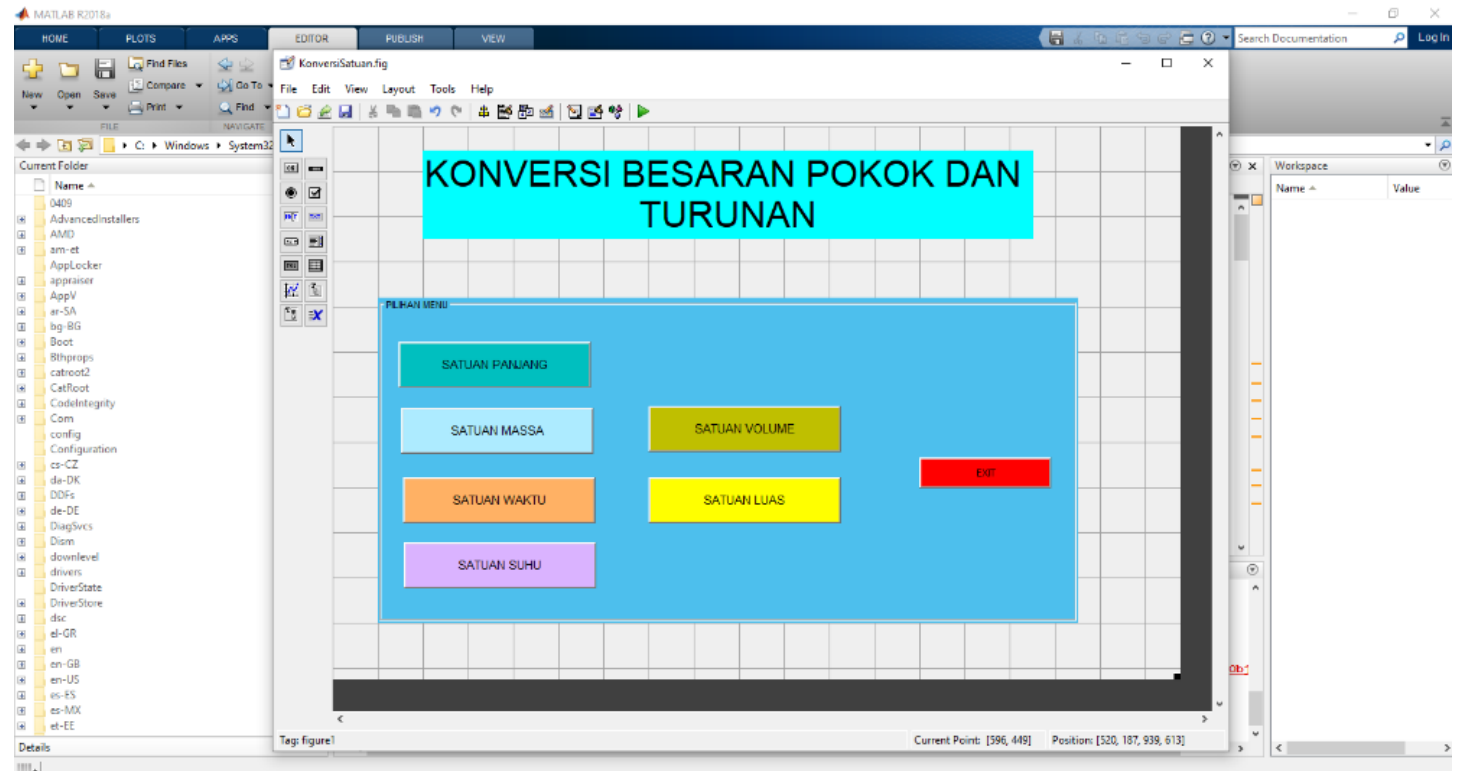

Gambar 2. Perancangan GUI pada tampilan awal 


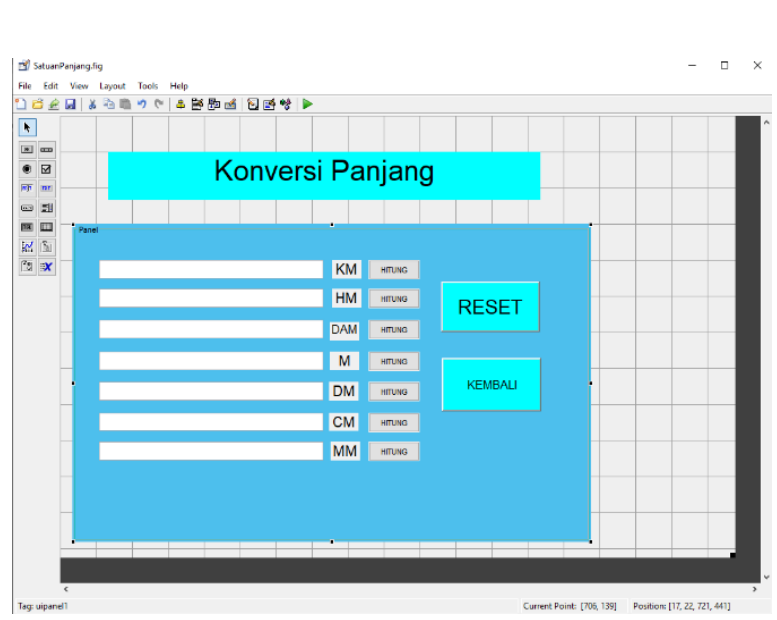

File Edit View Layout Tools Hel

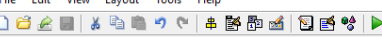

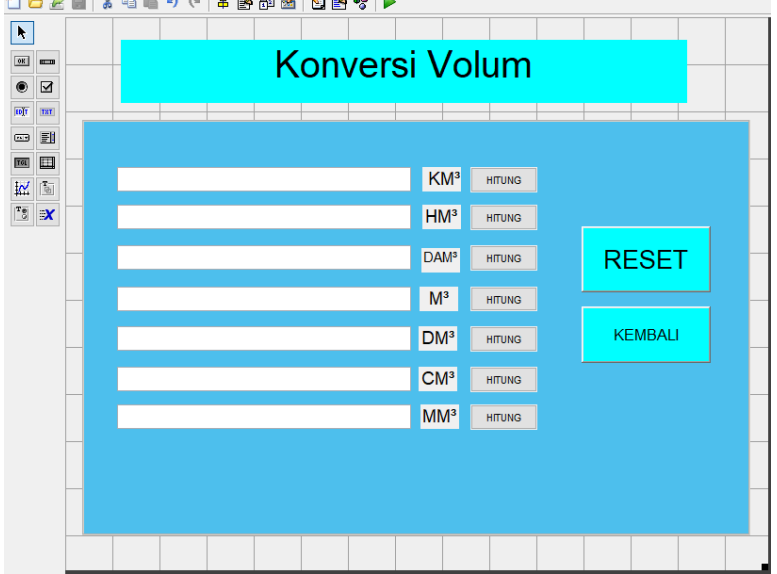

Gambar 3. Rancangan GUI pada konversi Panjang dan Volum

Adapun beberapa bagian coding yang diterapkan pada konversi Panjang dan volum, yaitu:

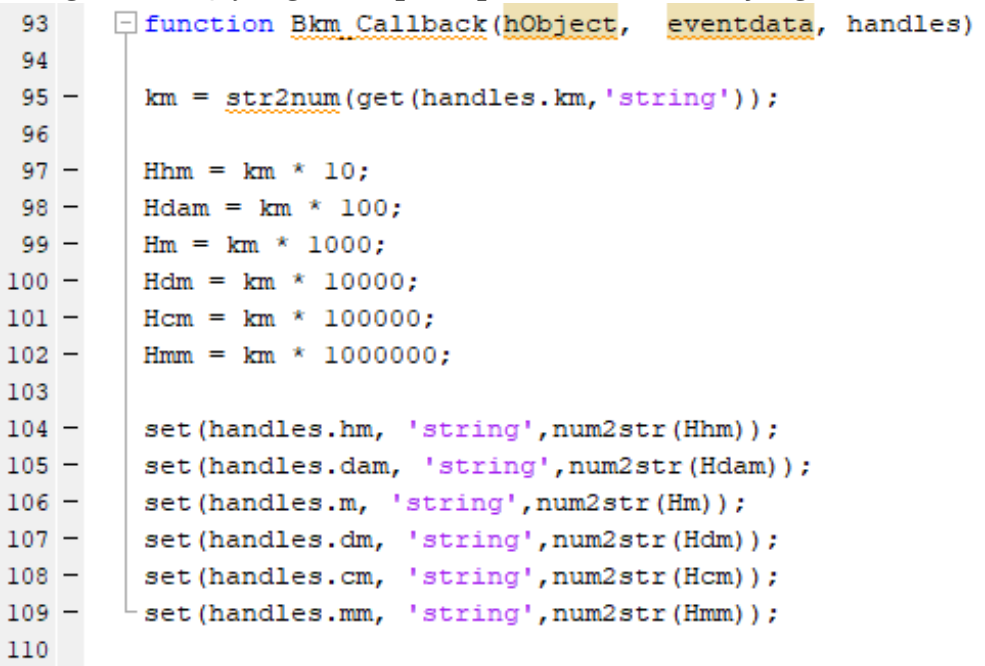

Gambar 4. Coding konversi Panjang

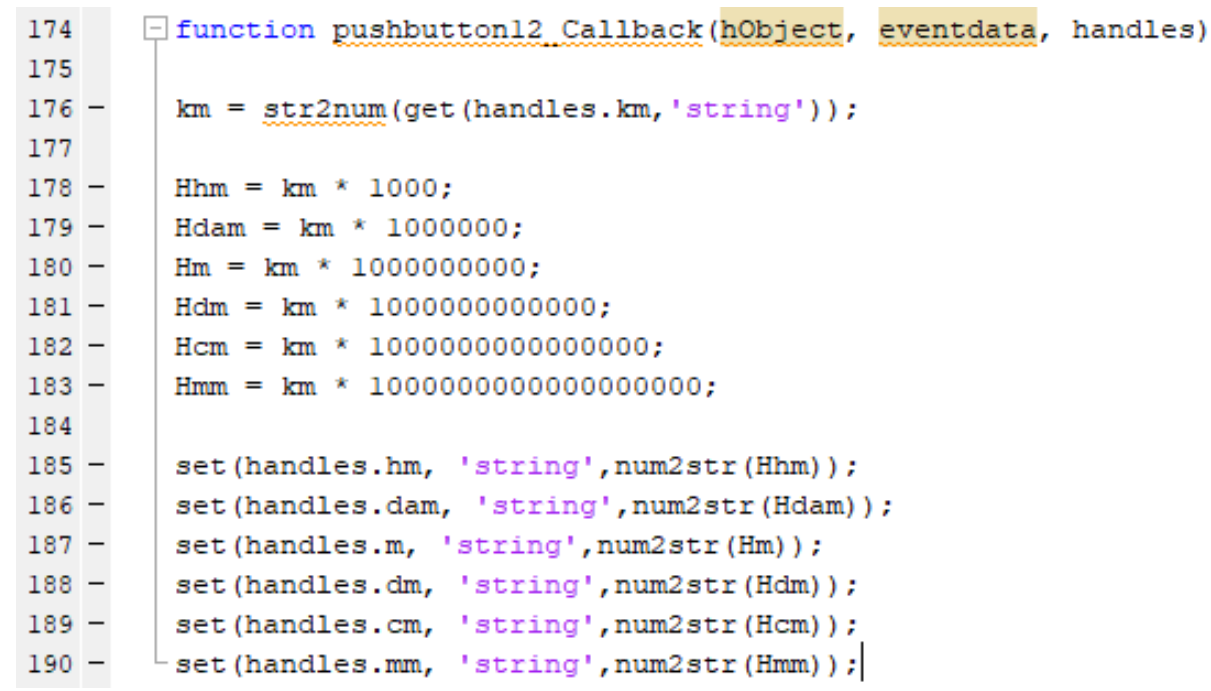

Gambar 5. Coding konversi Volum

Berikut tampilan konversi Panjang yang sudah di run: 


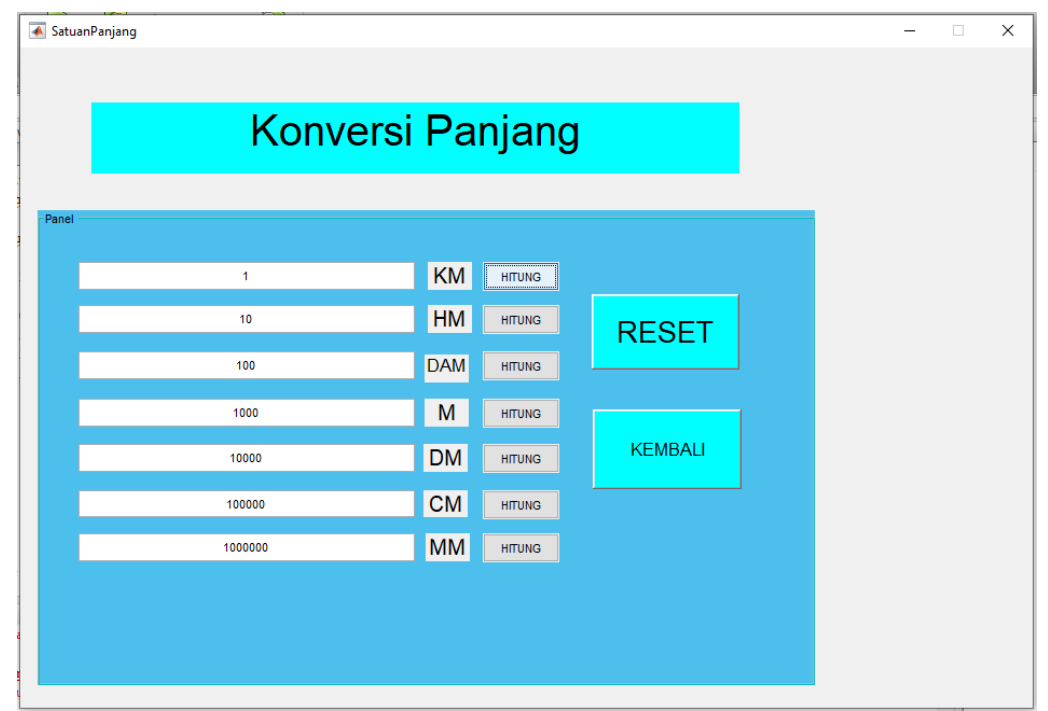

Gambar 6. Tampilan perhitungan konversi Panjang

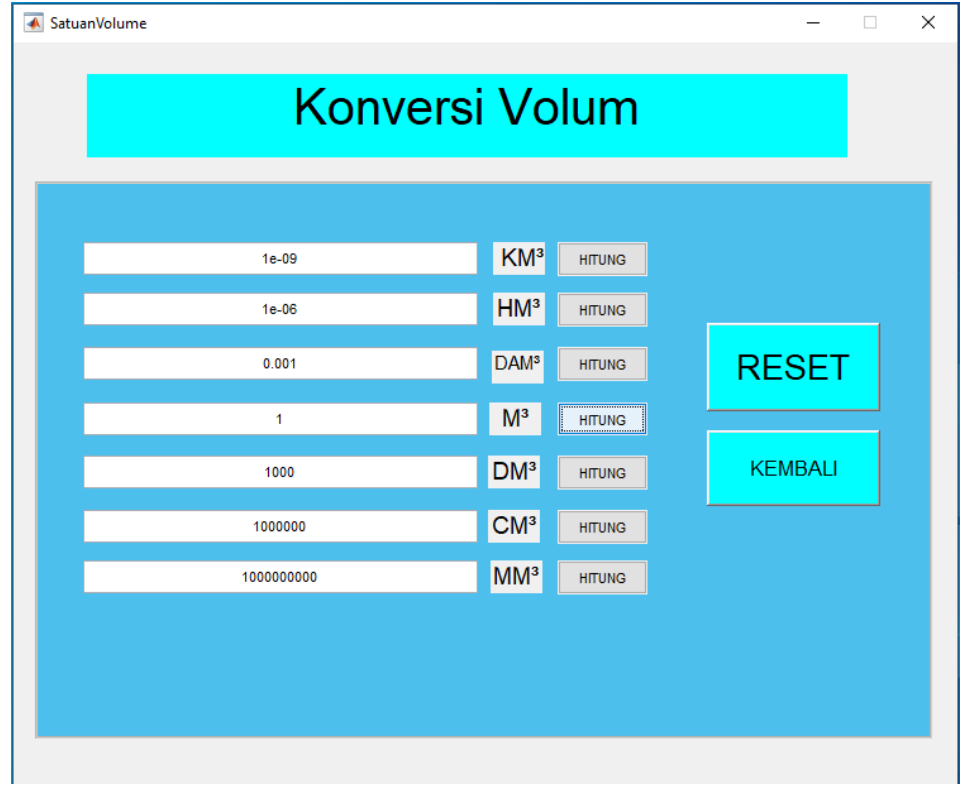

Gambar 7. Tampilan perhitungan konversi Volum

Tampilan aplikasi disertai dengan menu RESET dan KEMBALI. Dimana, menu RESET digunakan untuk mengosongkan perhitungan yang telah dilakukan sebelumnya, dan menu KEMBALI digunakan untuk kembali ke menu tampilan awal aplikasi dengan berbagai pilihan menu konversi.

Aplikasi konversi besaran pokok dan turunan ini, diimplementasikan ke mahasiswa Informatika, Universitas Indraprasta PGRI, sebagai alternatif media pembelajaran, dan motivasi dalam programming mata kuliah Fisika. Adapun hasil yang diperoleh, mahasiswa sangat antusias dengan program ini, dimana mahasiswa mampu memenuhi tugas lanjutan dengan materi berbeda berbasis Matlab.

\section{PENUTUP}

Aplikasi konversi besaran pokok dan satuan yang dibuat diperuntukkan khususnya bagi mahasiswa Informatika yang sedang mempelajari fisika, sehingga GUI dirancang sesuai target dan capaian RPS Fisika Gerak. Aplikasi ini dirancang menggunakan Matlab dengan tampilan GUI yang sederhana, sebagai pengenalan awal kepada mahasiswa. Dalam memperkenalkan tampilan GUI, juga diajarkan pembuatan coding nya agar selanjutnya mahasiswa dapat mengembangkannya lebih baik lagi. 


\section{DAFTAR PUSTAKA}

Alhidayatuddiniyah T.W., \& Siwi P.A. (2018). Seminar Nasional Edufisika 2018, Fisikawan Di Dalam Kelas: Implementasi Pembelajaran Karakter. Prosiding UHAMKA, (p. ed.3).

Astuti, S.P., \& Alhidayatuddiniyah T.W. (2019). Pemanfaatan Media Crocodille Physics Dalam Pembelajaran Untuk Meningkatkan Pemahaman Konsep Fisika. Navigation Physics: Journal of Physics Education, Vol.1, No.1, p. 1-5.

Giancoli, Douglas. (1997). Fisika 1 (Terjemahan). Prentice Hall. Jakarta: Erlangga.

Parwatiningtyas, D., \& dkk. (2016). Fisika Dasar. Jakarta: Unindra Press. 